\title{
Science Education: Principles
}

\author{
Joseph Agassi ${ }^{1}$ \\ Published online: 8 January 2020 \\ (c) Springer Nature B.V. 2020
}

The traditional method of science education has no discussion of education. All traditional education theory has almost nothing to do with education. There are two reasons for this. First is the idea, forcefully expressed by Immanuel Kant in his lectures on education: the only important item in schooling is education; the only important item in education is disciplining; and disciplining is achieved indirectly by instruction, so that what the content of the instruction is matters little. Kant's view is a mix of the traditional liberal idea-the only proper education is self-education — and the Prussian traditional idea-the most important aspect of character is discipline. Today the liberal idea is deemed impractical and the Prussian idea is deemed otiose. The second reason for traditional education theoreticians avoid discussing education is the claim that most of the practice of education of the young is the inculcation of values that takes place at home and in the religious Sunday School. This claim is true, yet clearly no excuse: the state does attend to the political or civic education of the young and it also intervenes in education whenever it finds necessary, usually in cases of national crises of all sorts. The commonest standard item in public education is education for patriotism, and its normal and desirable form is that of education for democracy and for civic responsibility.

The trouble with traditional political education for democracy is that it is done undemocratically. The exception is the democratic school or the free school that practices democracy: in addition to the state laws and the local ordinances it legislates by direct democracy what are the rights and duties of the members of the school, the procedures for entrance and for graduation, etc. The most important debate about political education in schools centres on the choice between traditional and free education. It is a discussion about the very possibility of free education, since those who admit that it is possible advocate itexcept for those who are in principle opposed to democracy. Important as the opposition to democracy is, it will be ignored here, so that the dispute about free education will here be considered a practical issue.

Leaving then education proper, what remains of education theory has to do with instruction proper: what to teach, at what pace, and how to make reluctant pupils receive instruction. In traditional schools, decisions on such matters are made centrally-by the national or city department of education-whereas in free schools it is done locally within the law. For the law of the land usually determines what is the minimal compulsory part of compulsory education. It is usually viewed as the three r's. This is very

Joseph Agassi

agass@tauex.tau.ac.il

1 Tel Aviv University and York University, Toronto, Canada 
vague, since obviously there are levels of literacy and of arithmetic. Yet the vagueness is usually unproblematic as local traditions explicate this with little or no dissent. In addition, there is the great gulf between state schools and church schools regarding religious instruction. Usually, the state recognizes church schools and supports them financially on the condition that they undergo some sort of state supervision. We need not go into these matters either, since they are determined by tradition in almost all modern liberal democratic nation-states. In the exceptions, such as Israel, religious instruction creeps into non-religious schools and it threatens the very democratic character of the state. It is impossible to discuss this matter without entering deeply into political issues. And so we have to let it go.

As to the material that traditional schools in normal democracies transmit- the curriculum-no matter how democratically this matter is decided, the transmission itself is done authoritatively: the teacher knows what the pupil does not know, so that there is no way to teach it but authoritatively. The very important and interesting philosophy of science of Michael Polanyi rests on this obvious claim. Polanyi considered training for research a major task of university education, and the ability of researchers for independent thinking a major characteristic of researchers. Yet he declared that students must recognize the authority of the professor and yield to it. Nor can we expect the professor to be able to express any principles of education or describe the way education takes place. Professors possess the knowledge of their task but it is not articulated knowledge; he called it "personal knowledge". It is thus impossible to control university teaching: we judge it by its fruits, much the way we judge art education in art workshops. Indeed, Polanyi viewed scientific research more similar to art workshops than any philosopher before him.

All this did not treacle to elementary school, whose conduct is greatly influenced by traditional education theory that is really the theory of instruction proper: what to teachcurriculum - at what pace-didactics - and how to make reluctant pupils receive instruction-motivation. As to the curriculum, it is usually not in the hands of educators but in the hands of politicians. True, they listen to educators, but they also must listen to the public that elects them. In particular, whereas educators all agree that the well-educated citizen has to be in possession of some familiarity with both the arts and the sciences, to be somewhat well-rounded, most educated citizens want the education of their children to cater first and foremost for their acquisition of proper means of livelihood; at times they even express hostility to the educators' ideal.

And so, it seems, we must leave the curriculum as given and stay with the ways of instruction. These, to repeat, are traditionally deemed authoritarian. There was an attempt to rebel against traditional instruction. It is the discovery method, also known as open learning or experimental learning: do not teach students but offer them information and hints and allow then to discover the ideas that rest on that information all by themselves. This is a priori simply silly, since the curriculum is dictated to them so that the most important aspect of their study, the choice of material to study, is not in their hand. This is not the worst of it. The worst is the suggestion that ordinary or even bright students can discover what hundreds of ingenious researchers were fortunate to discover. This is absurd. There is no need, as the saying goes, to rediscover the wheel and it is even scarcely possible. The discovery method added to the idea that teachers can suggest information and hints about the discovery also the problems to tackle. This is a great help, indeed, since discovering a problem is no small matter, and as the famous proverb has it, a problem well put is half the solution. Yet even then, the distance between the half-solved problem and the solution is too big even when hints are thrown in as bridges of sorts. 
The difficulty remains: the materials that students have to master is thrusted on the students who cannot comprehend what is going on. It is worse than pulling rabbits out of top-hats: it is not even clear what is drawn out of the top-hat. Is there a better way to teach?

The traditional role of the teacher is doubtlessly authoritative. This has led philosophers of the Enlightenment Movement to the suggestion that learning is better achieved with no teacher: let Nature instruct you: open up to Mother nature and observe Her marvels. Members of the Enlightenment Movement pretended that they were self-educated universal experts; they read scientific papers while repeating the experiments that they describe. This ensured that the growth of science put an end to that movement.

The sad fact is that long before that early in the history of that movement the more reasonable alternative was found to the submission to the authority of the teacher and rebelling against it: the alternative was due to John Locke, one of the fathers of the movement. He suggested that pupils should have tutors who should be at the student's beck and call yet without showing any incentive. How adequate is Locke's answer?

We do not know. It is tried out, if at all, only in free schools. These are schools with teachers but without coercion to study. As far as free schools practice what they preach and as far as their success rate is studied and as far as the extant studies of this matter are reliable, then there is no difference in worldly achievement between the average pupils of ordinary and free education. If this is so then certainly free education is to be preferred.

There is a great opposition to free schools and anyone who contemplates support for them might benefit from examining them.

The first objection to free schools is the argument against anarchism: without submission to some authority there is no social order and thus no society. This objection is easy to dismiss: free schools are not anarchist: they abide by state and local laws and ordinance. In particular, the anti-anarchists fear sexual permissiveness, especially in free boardingschools. To the extent that this case is problematic, it is no less problematic in traditional boarding-schools than in free ones.

The second objection to free schools is the argument against its free curriculum: it will lead students to choose frivolous items rather than he important items (whose importance they are ignorant of and indifferent to). This objection is in distrust of both the curiosity that normal humans naturally possess and the democratic regime that helps individuals learn about the importance of new items. Also, behind this objection stand the taboo against the study of unhealthy topics, namely sex. (George Orwell's semi-autobiographic 1935 novel Clergyman's Daughter narrates a case where a teacher's mere mention of the word "womb" in school led to her dismissal.) And, indeed, in free school pupils do ask to be told about sex. What happens there fairly regularly is that teachers tell them about reproduction and then they lose interest: as Bertrand Russell has noted, much of the interest in sex is due to the taboos around information about it.

The objection to free schools from the curriculum is often from practical considerations: in order to be economically independent one has to acquire some skills and this requires some boring training that children will not undertake freely. This is a strong argument, since certainly school has to prepare the young for life of economic independence. The question, however, is empirical. Too many constraints on individual freedom were imposed in the name of the protection of society that turned out to be unnecessary. We have to examine empirically: do graduate of free education do better or worse than graduates of traditional education? There is little research on this matter, and its statistics is of doubtful reliability. For what it is worth, it shows no advantage of any one system over the other. We have to consider this argument either questionable or invalid. And clearly the right to impose on children requires a better empirical basis than what we have. 
The third objection to free schools is from discipline; they do not develop individual discipline. This is an empirical question too, and it is even harder to decide by empirical means. We do not know how much discipline is required; we do know that it must come with some flexibility or else it may be disastrous. What discipline is and what flexibility is we know only vaguely; we know that for this we need also a third quality, that of critical ability. And on this there is no general rule: some schools sharpen their students' critical ability, some not (with the possible exception of traditional rabbinical schools-yeshivoth - that are rightly or wrongly acclaimed for their ability to inculcate the critical attitude).

The criticism of the free schools is thus either invalid or inconclusive. Not so the criticism of traditional schools. This may be not very surprising since free schools are in a sense elitist and traditional schools are forced by the law of compulsory education to suffer the burdened of catering for the whole population (minus the elite that can find better schooling). Also, traditional education suffers from a long tradition of many errors that it had to free itself from. Nevertheless, considering the practice that most schoolchildren are subject to, we should examine them carefully and try to neutralize the damage they do.

To repeat, education theory centres on the curriculum, motivation and didactics. On the curriculum we have to expand on daily basis as it alters in accord with the alterations of what is available and what we need. As to motivation studies, they are outrageous: rather than to appeal to the interests that humans have naturally, they examine artificial means to raise them. This means, what lies should we tell our pupils? We should tell them the truth. The trouble is, we do not want to discus with them their interests, not even critically. This means, we are ashamed. We should alter our ways so as to be in no reason for shame. A critic of motivation theory was Maria Montessori, the first Italian woman to receive a medical degree. She reports in her autobiography that she once saw a little girl playing, sitting on the floor; she lifted her and noted that she was so absorbed in her play that she did not notice being lifted. Montessori reports that she learned from this at once that all the information on which educational theories rested was false. She developed a teaching method that mixes teaching with play. This idea is unpleasant in its consideration of learning as swallowing a bitter pill, and it is very pleasant in its sensitivity to pain: if you must administer a bitter pill, better administer it sugar-coated. Yet learning is not bitter: it is a joy. That pupils do not see this is due to our teaching methods that turn the joy into suffering. We have to seek a less painful method: we have to find out how we spoil it.

There remains didactics. It is the study of teaching methods. What is common to them all is the idea that learning is passive. Learning theory tells us of three learning methods: passive reading, passive hearing and active. Of course there are many methods of active learning. They are not specified in this context because they are dismissed: teachers can be in better control when pupils are passive. Still, according to learning theory, active learning is always better than passive learning. When a teacher, especially in university, invites students to participate actively in the progress of the study by asking questions and by making spontaneous comments, most students prefer to be passive. This is evidence for the tremendous success of the traditional methods of instruction: students deceive themselves that the learn better in the passive mood.

Since didactics assume that students are passive, the main question is, how fast can the teacher progress? Going too fast leaves the students behind and too slow bores them. The right method is displayed by students passing exams with flying colours. The ideal pupil then makes no mistakes. This is the worst education possible: it renders its graduates utterly dependent. 
So far we have discussed education in general, not science education that is the topic of this essay. We have to see what makes science such an obstacle for so many students. We have to realize that this is the result of education: too many graduates hate poetry and too many hate science; this is not due to nature but to nurture. Even students of technical schools may hate science: they may be good at technology, and thereby also of sciencerelated technology and so also at some aspect of science proper. For they see the point of the science that they master. We can see that even in science unrelated to technology or even in pure mathematics. Students of mathematics learn about matrices and matrix addition with ease, but get stuck with matrix multiplication. This is not so: when they learn in algebraic geometry that rotation is represented by unitary matrices and that the addition of two rotations is represented by the product of the two representative unitary matrices, then, all of a sudden, the rule of product of matrices starts making sense. This holds not only for students of mathematics: it holds for first graders just as much. Pre-schoolers learn to count, to count odd numbers, even numbers, fives and tens. It is $1+1=2$ that kills them. The teacher usually takes it as given that some children have troubles with arithmetic tables; this is not true: they have trouble with the use of arithmetic tables: they see none. The teacher's error only aggravates the situation to the point of branding some of the more curious and independent-minded first-graders as unfit for math.

The point can be generalized; science teachers pull rabbits out of top hats. Pupils are stunned by their lack of comprehension that their teachers misunderstand as the failure of their pupils to see the rabbit when they fail to see where it comes from. And the reason for the teacher's error is the teacher's own ignorance.

Example. The discovery that the evening star and the morning star are identical. This is one of the greatest discoveries in astronomy. Most educated people know it. Ask them, how was this discovery made, and they will be unable to say anything about it. The answer is, ancient astronomers plotted the paths of both stars and found that they are identical with each other. Before saying this one has to say, why did astronomers wish to draw the paths of stars.

Another example. Galileo saw caters on the moon. How? Same story. In historical truth he did not discover craters: he discovered mountains and seas on the moon. Except that there are no mountains on the moon and no water. What he saw we consider craters. And he saw a mountain by fixing his telescope on a dark spot on the moon and saw it disappear as a shadow on an earthly mountain disappears on sunrise. And he saw water on the moon as he declared the dark insides of craters as lakes. For, he made a great discovery about reflection. When asked is a mirror on the wall brighter or darker than the wall, we tend to say, it is brighter. Leonardo da Vinci said so. Vincent van Gogh drew a mirror like that. Galileo showed that this is not so: when the sun shines on a mirror, most of the sunlight that hits the mirror is reflected in one direction; standing at the right angle we see the mirror blindingly bright and in all other angels it is dark. The wall, said Galileo, comprises thousands of small mirrors facing different angles and so the sunlight is reflected in all directions, making the wall bright.

There is a moral from the story: we teach the discovery in a corrected version and then it turns out a rabbi out of a top hat. Consider the case of the discovery of the meson, the particle whose size is between that of a proton and an electron (from the Ancient Greek meson means middle). Yukawa assumed that it exists and calculated its size. He got it wrong. Historians tend to report the discovery but not the error. That prevents them from explaining how he came to his idea. That makes it a rabbit out of a top hat.

When spectral lines were discovered and identified as characteristics of the atoms that radiate discontinuous colours, this opened up the study of the chemical structures of stars. 
And so the element helium was found first on the sun and then on earth. The fact that this was first conjectural and that there at least two other elements were claimed to be found on the sun historians of science do not report, although it makes the discovery of helium much less a rabbit out of a top hat.

These are examples of discoveries in physics that teachers dump on their pupils because they do not know how to present the facts more reasonably than just as given. In mathematics things are worse. Imre Lakatos 1970 Proofs and Refutations is largely the unpacking of the cumbersome definition of the polyhedron to show that it comes to exclude the bodies that may be considered polyhedra but do not obey the law of polyhedra known as the Descartes-Euler theorem. Many teachers told me that this is very nice but they cannot use it in class because they have a curriculum to cover. This response is both not to the point and false: teaching the material with as little pulling rabbits out of top hats as possible accelerates teaching and, above all, reduced the rate of dropouts from math and science courses.

Publisher's Note Springer Nature remains neutral with regard to jurisdictional claims in published maps and institutional affiliations. 